\title{
Badania właściwości złączy lutospawanych aluminium ze stalą wykonanych przy użyciu spoiw na bazie Al i Zn
}

\author{
Research on the properties braze-welded joints aluminum \\ with steel using filler metals on Al and Zn matrix
}

\section{Streszczenie}

W artykule przedstawiono problematykę związaną z łączeniem cienkich blach ze stali ocynkowanej, które lutospawano ze stopem aluminium 5754. Złącza wykonano niskoenergetyczną metodą CMT na stanowisku zrobotyzowanym przy użyciu spoiw na bazie aluminium (AISi5) oraz cynku (ZnAl15). Wyniki badań wizualnych i metalograficznych złączy zakładkowych potwierdzają ich wysoką jakość, bez śladów naruszenia powłoki cynkowej w pobliżu spoiny. Przedstawiono również wyniki wytrzymałości na ścinanie złączy zakładkowych w zależności od rodzaju użytego spoiwa. Wykazano, że użycie spoiwa o niższej temperaturze topnienia umożliwia uzyskanie złączy o większej wytrzymałości mechanicznej.

Słowa kluczowe: lutospawanie; złącza różnoimienne; właściwości złącza

\begin{abstract}
The problems related to joining thin sheets of galvanized steel with aluminum alloy 5754 was presented in this article. The joints were made by low-energy CMT method at robotized set-up using filler metals on aluminum (AISi5) and zinc (ZnAl15) matrix. The results of the visual and metallographic tests of overlap joints confirm their high quality, without any evidence of a zinc coating near the weld. The results of the shear strenght of overlap joints are also presented, depending on the type of used filler metals. Finally, the significant effect of the use of lower melting temperature filler metal to obtain joints with higher mechanical strenght was demonstrated.
\end{abstract}

Keywords: MIG brazing; heterogeneous joint; joint's properties

\section{Wstęp}

Obserwując obecne trendy rozwojowe w spawalnictwie można zauważyć, że często zmierzają one w kierunku łączenia elementów o małych przekrojach i małej grubości, również w konfiguracjach różnoimiennych. Coraz częściej łączy się ze sobą materiały różniące się znacznie między sobą pod względem właściwości fizykochemicznych i mechanicznych. Spowodowane jest to m.in. względami ekonomicznymi i ekologicznymi. W przemyśle motoryzacyjnym, lotniczym czy kosmicznym dąży się do znacznej redukcji masy, przy jednoczesnym zachowaniu często bardzo rygorystycznych wymagań eksploatacyjnych [1].

Łączenie ze sobą materiałów o różnych właściwościach fizykochemicznych przy użyciu tradycyjnych metod spawalniczych jest utrudnione lub nawet często niemożliwe do wykonania. Z tego względu w ostatnich latach coraz większego znaczenia nabiera technologia lutospawania. Obok tradycyjnych metod lutospawania łukowego w osłonie gazów, dynamicznie rozwijane są metody niskoenergetyczne oraz metody wykorzystujące jako źródło ciepła np. promień lasera lub wiązkę elektronów [2]. Powstała nowa generacja urządzeń w zakresie niskoenergetycznego lutospawania, dzięki której zwiększona jest kontrola nad ilością ciepła wprowadzonego do strefy łączenia. Dużego znaczenia w kontroli nad energią spawania nabrało zastosowanie cyfrowego sterowania przebiegiem napięcia i natężenia w każdej fazie przejścia kropel metalu spoiwa w łuku. Nastąpił rozwój niskoenergetycznych metod technologicznych: STT - Lincoln Electric (procesem spawania łukiem zwarciowym ze sterowaniem przenoszenia metalu siłami napięcia powierzchniowego), ColdArc - EWM (wszystkie regulacje procesu są przeprowadzane bezpośrednio w źródle zasilania, bez mechanicznej ingerencji w podawanie drutu), CBTO - Daihen (zmniejszenie ilości rozprysków osiąga się poprzez sterowanie wielkością natężenia prądu w momencie końca zwarcia i początku jarzenia łuku) oraz użyta w niniejszych badaniach metoda CMT - Fronius [3,5].

Dr inż. Tomasz Wojdat, dr inż. Paweł Kustroń, dr inż. Artur Lange, Izabela Łącka - Politechnika Wrocławska.

Autor korespondencyjny/Corresponding author. artur.lange@pwr.edu.pl 
Metoda CMT( ang. Cold Metal Transfer) to proces spawania łukiem zwarciowym z innowacyjną technologią oddzielania kropli stopionego metalu od końca drutu elektrodowego. Polega ona na zajarzeniu tuku i podaniu drutu do jeziorka, drut jest podawany aż do momentu zaistnienia zwarcia, w czasie zwarcia kierunek posuwu drutu ulega odwróceniu i następuje jego okresowe wycofanie (z częstotliwością rzędu $70 \mathrm{~Hz}$ ), kiedy zwarcie zostaje przerwane drut jest ponownie podawany w stronę jeziorka [7].

Technologia CMT ma wiele zalet, najważniejszą jest zminimalizowanie natężenia prądu podczas zwarcia, co powoduje przekazywanie do elementu tylko bardzo małej ilości ciepła. Umożliwia ona spawanie i lutospawanie praktycznie bez rozprysków, poprawia warunki pracy przez ograniczenie emisji dymów spawalniczych oraz zwiększa wydajność produkcji. Metodą tą uzyskuje się poprawnie wykonane złącza o wysokiej jakości, lepszych właściwościach wytrzymało-

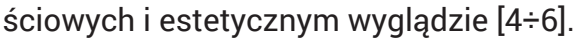

Znajduje ona praktyczne zastosowanie zwłaszcza przy spawaniu cienkich blach ze stali niestopowych, wysokostopowych i nierdzewnych oraz stopów aluminium, a także przy wykonywaniu lutospawanych połączeń różnoimiennych m.in. aluminium ze stalą $[5,7]$.

\section{Materiały zastosowane w badaniach}

Próby lutospawania przeprowadzono na cienkich blachach o grubości 1,0 mm. Proces przeprowadzono na zrobotyzowanym stanowisku spawalniczym (rys. 1), którego najbardziej istotnymi elementami są: źródło prądu TransPuls Synergic 3200 CMT (1), podajnik drutu VR 7000-CMT 4R/G/W/F++ (2) połączony elastycznymi przewodami z robotem Kawasaki serii BA (3) wyposażonym w uchwyt spawalniczy Robacta Drive CMT PAP W (4).

Wykonano złącza, w których łączono na zakładkę (rys. 2) blachę ze stali niskowęglowej DX51D ocynkowaną ogniowo, o grubości powłoki $14 \mu \mathrm{m}$, z blachą ze stopu aluminium 5754 . Zarówno stop 5754, jak i blacha ocynkowana odznaczają się dużą odpornością na korozję w warunkach morskich i atmosferze przemysłowej. Skład chemiczny i podstawowe właściwości stopów wybranych do badań przedstawiono w tablicy 1 .

Materiał dodatkowy do lutospawania stanowiły spoiwa na bazie aluminium AISi5 i cynku ZnAl15, oba o średnicy $1,0 \mathrm{~mm}$. Skład chemiczny spoiw wraz z ich temperaturą topnienia przedstawiono $\mathrm{w}$ tablicy 2 .

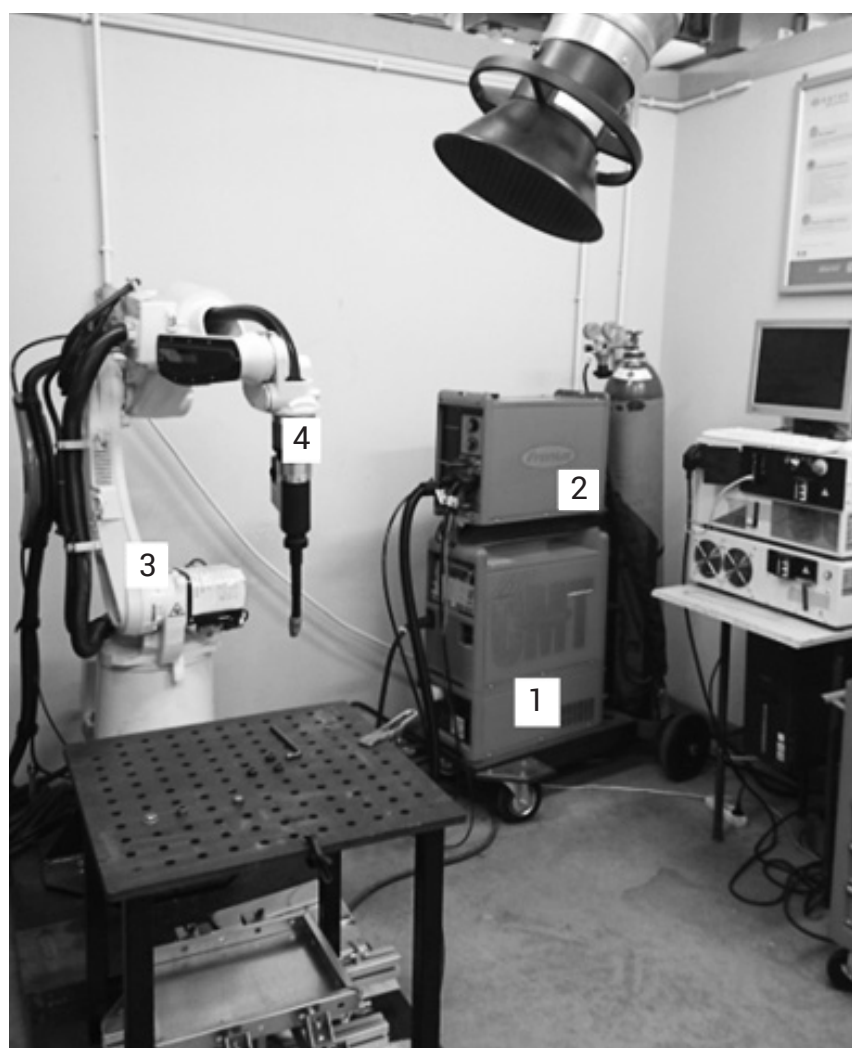

Rys. 1. Stanowisko do zrobotyzowanego spawania metodą CMT Fig. 1. The robotized set-up for CMT welding
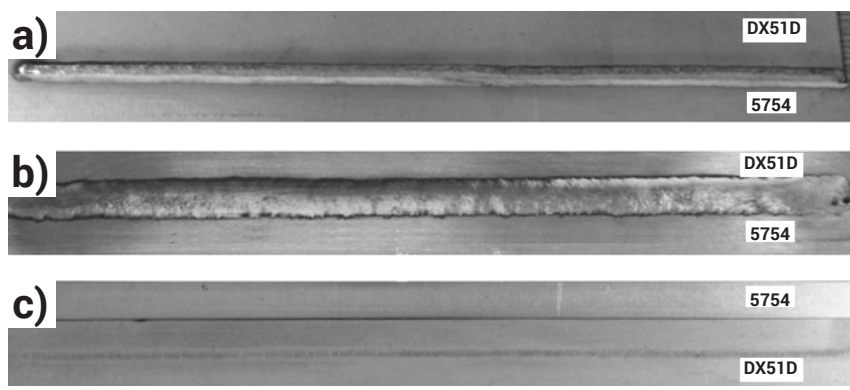

Rys. 2. Złącza próbne lutospawane metodą CMT: a) lico spoiny wykonanej spoiwem AlSi5, b) lico spoiny wykonanej spoiwem ZnAl15 i c) strona odwrotna złącza

Fig. 2. The view of test braze-welded joints by CMT method: a) weld face made of AISi5 filler metal, b) weld face made of ZnAl15 filler metal and c) opposite side of joint

Tablica I. Skład chemiczny i podstawowe właściwości stopu aluminium 5754 i stali DX52D + Z200 [8 $\div 10]$

Table I. Chemical composition and basic properties of aluminium alloy 5754 and DX52D + Z200 steel [8 $\div 10$ ]

\begin{tabular}{|c|c|c|c|c|c|c|c|c|c|c|}
\hline Oznaczenie & \multicolumn{6}{|c|}{$\begin{array}{l}\text { Skład chemiczny } \\
\text { [\% wag.] }\end{array}$} & $\begin{array}{c}\text { Temperatura } \\
\text { topnienia } \\
{\left[{ }^{\circ} \mathrm{C}\right]}\end{array}$ & $\begin{array}{l}\text { Gęstość } \\
{\left[\mathrm{kg} / \mathrm{dm}^{3}\right]}\end{array}$ & $\begin{array}{c}\text { Wytrzymałość } \\
\text { na rozciąganie } \\
\text { Rm [MPa] }\end{array}$ & $\begin{array}{c}\text { Wydłużenie } \\
\text { względne } \\
\text { A_[\%] }\end{array}$ \\
\hline \multirow{2}{*}{ Al 5754} & Al & $\mathrm{Mg}$ & $\mathrm{Zn}$ & $\mathrm{Mn}$ & $\mathrm{Si}$ & $\mathrm{Cr}$ & \multirow{2}{*}{$595 \div 645$} & \multirow{2}{*}{2,67} & \multirow{2}{*}{$190 \div 200$} & \multirow{2}{*}{$10 \div 14$} \\
\hline & reszta & $2,6 \div 3,6$ & 0,2 & 0,5 & 0,4 & 0,3 & & & & \\
\hline \multirow{2}{*}{ DX51D } & C & $\mathrm{P}$ & S & $\mathrm{Mn}$ & $\mathrm{Si}$ & $\mathrm{Ti}$ & \multirow{2}{*}{1497} & \multirow{2}{*}{7,86} & \multirow{2}{*}{$270 \div 500$} & \multirow{2}{*}{$20 \div 22$} \\
\hline & 0,18 & 0,12 & 0,045 & 1,2 & 0,5 & 0,3 & & & & \\
\hline
\end{tabular}


Niezależnie od użytego spoiwa otrzymano lutospoiny o wysokiej jakości, równej szerokości lica i bez widocznych niezgodności zewnętrznych. Zarówno od strony lica, jak i po przeciwnej stronie złącza nie ma uszkodzeń ochronnej powłoki cynku oraz nadtopień stopu aluminium 5754.

Tablica II. Skład chemiczny i temperatura topnienia lutów AlSi5 i ZnAl15 [11]

Table II. Chemical composition and melting point of AlSi5 and ZnAl15 filler metals [11]

\begin{tabular}{|c|c|c|c|c|c|}
\hline \multirow{2}{*}{ Spoiwo } & \multicolumn{4}{|c|}{ Skład chemiczny [\% wag.] } & \multirow{2}{*}{$\begin{array}{c}\text { Temperatura } \\
\text { topnienia } \\
{\left[{ }^{\circ} \mathrm{C}\right]}\end{array}$} \\
\hline & Al & $\mathrm{Mg}$ & $\mathrm{Si}$ & $\mathrm{Zn}$ & \\
\hline AlSi5 & reszta & $<0,05$ & $4,5 \div 5,5$ & $<0,1$ & $573 \div 625$ \\
\hline ZnAl15 & $14 \div 16$ & - & - & reszta & $382 \div 450$ \\
\hline
\end{tabular}

\section{Statyczna próba ścinania}

Do statycznej próby ścinania, ze złączy zakładkowych pokazanych na rysunku 2, wycięto próbki o szerokości $30 \mathrm{~mm}$, które następnie frezowano w spoinie na wymiar $12 \mathrm{~mm}$. Statyczną próbę ścinania przeprowadzono na uniwersalnej maszynie wytrzymałościowej Louis Schopper o napędzie hydraulicznym. Prędkość posuwu belki poprzecznej wynosita $0,2 \mathrm{~cm} / \mathrm{min}$, a zakres pomiarowy do $10 \mathrm{kN}$.

Średnia wytrzymałość złączy wykonanych przy użyciu spoiwa AlSi5 wynosiła $105 \mathrm{MPa}$, a złączy wykonanych przy użyciu spoiwa ZnAl15 - $185 \mathrm{MPa}$. Niezależnie od rodzaju użytego spoiwa do zniszczenia złącza za każdym razem dochodziło w strefie wpływu ciepła stopu 5754 i częściowo w lutowinie (rys. 3). Biorąc pod uwagę taki sam rodzaj i umiejscowienie zniszczenia próbek, większa o ok. $75 \%$ wytrzymałość mechaniczna złączy wykonanych przy użyciu spoiwa cynkowego wynika najprawdopodobniej ze znacznie mniejszego stopnia przegrzania blachy ze stopu aluminium 5754 w SWC. Wytrzymałość stopu aluminium 5754, z którego wykonano próbki przed procesem lutospawania wynosiła 192 MPa. Użycie spoiwa Zn nie wpływa zatem znacznie na obniżenie właściwości mechanicznych stopu aluminium jak ma to miejsce w przypadku spoiwa na bazie Al.
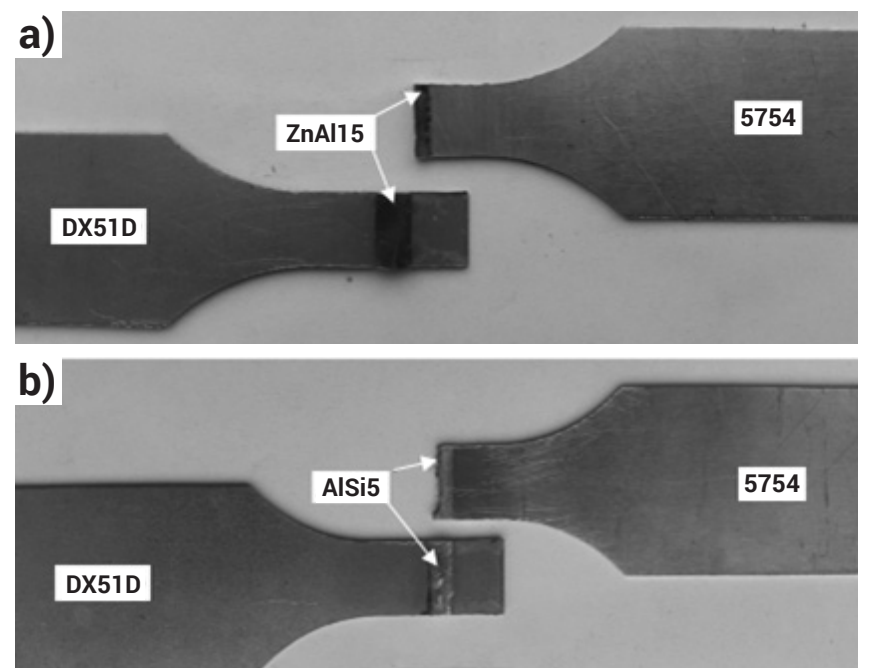

Rys. 3. Przykładowe przełomy złączy lutospawanych wykonanych przy użyciu spoiwa: a) ZnAl15 i b) AlSi5

Fig. 3. Exemplary fractures of braze-welded joints made using a filler metals: a) ZnAl15 and b) AlSi5

\section{Badania metalograficzne}

Z wykonanych złączy wycięto próbki, które następnie zainkludowano w żywicy epoksydowej w celu przygotowania zgładów metalograficznych. Zgłady metalograficzne szlifowano na papierach ściernych o gradacji od 400 do 2500 , a następnie polerowano przy użyciu zawiesiny tlenku glinu $\mathrm{Al}_{2} \mathrm{O}_{3}$ o wielkości ziaren $0,3 \mu \mathrm{m}$ i trawiono odczynnikiem Kellera. Tak przygotowane zgłady metalograficzne poddano badaniom mikroskopowym przy użyciu mikroskopii świetlnej. Obserwację makrostruktur złączy lutospawanych wykonano na mikroskopie Olympus SZX7, natomiast obserwacje mikroskopowe przeprowadzono na mikroskopie Olympus CK40M. Na rysunku 4 pokazano przykładowe makrostruktury badanych złączy.

W przypadku złączy wykonanych przy użyciu spoiwa AISi5 uzyskano płaskie lico spoiny świadczące o dobrym zwilżaniu stali ocynkowanej przez spoiwo. W samej spoinie widoczne są natomiast liczne pory gazowe, które jednak nie stanowią zagrożenia dla prawidłowej funkcjonalności złącza. Lutospoina utworzona ze spoiwa ZnAl15 jest bardziej wybudowana do góry (mniejsza zwilżalność stali ocynkowanej), lecz posiada mniejszą ilość niezgodności w postaci pęcherzy gazowych usytuowanych jedynie w jej górnej części. Niezależnie od rodzaju użytego spoiwa doszło do wtopienia w blachę stopu aluminium 5754 .
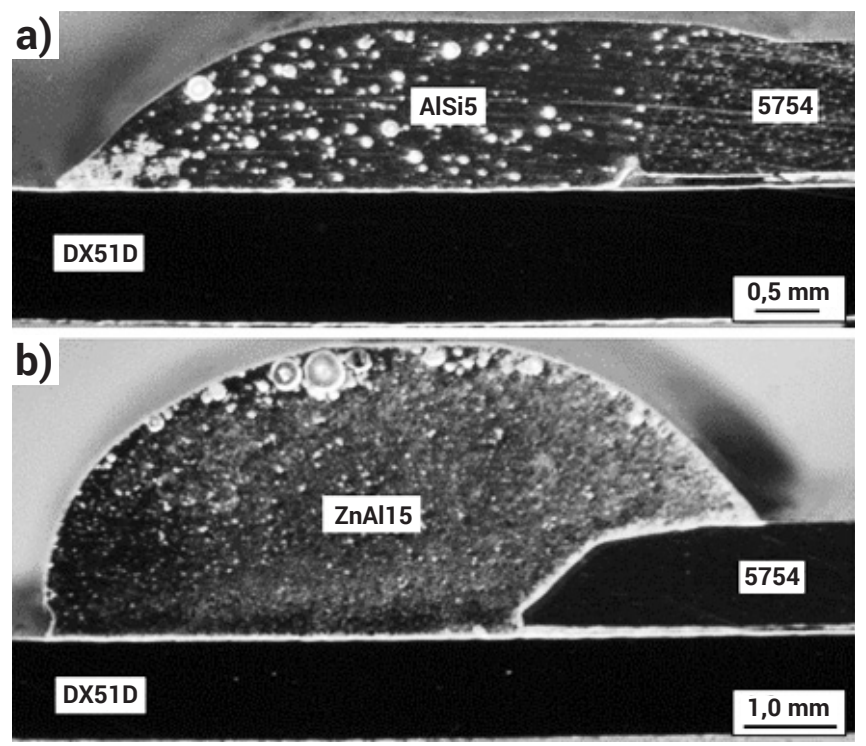

Rys. 4. Makrostruktury złączy lutospawanych przy użyciu spoiwa: a) AlSi5 i b) ZnAl15

Fig. 4. Macrostructure of braze-welded joints using a filler metals: a) AlSi5 and b) ZnAl15

Na rysunku 5 pokazano mikrostrukturę złączy w strefie początkowej lutospoiny.

W żadnym z przypadków nie doszło do uszkodzenia powłoki Zn w obrębie złącza. Na długości złącza doszło natomiast do częściowego rozpuszczenia cynku z powłoki w stopiwie, w związku z czym jej grubość uległa zmniejszeniu z $14 \mu \mathrm{m}$ do ok. $3 \div 5 \mu \mathrm{m}$.

W lutospoinie utworzonej ze spoiwa AISi5 widoczne są dendryty roztworu stałego a i eutektyki a+Si z układu równowagi fazowej stopów Al-Si, rozmieszczone w przestrzeniach międzydendrytycznych (rys. 6a), natomiast w lutospoinie ze spoiwa ZnAl15 występują dendryty roztworu stałego $\eta$ oraz eutektyki $\eta+a$ z układu równowagi fazowej stopów Zn-Al rozmieszczonej w przestrzeniach międzydendrytycznych. 

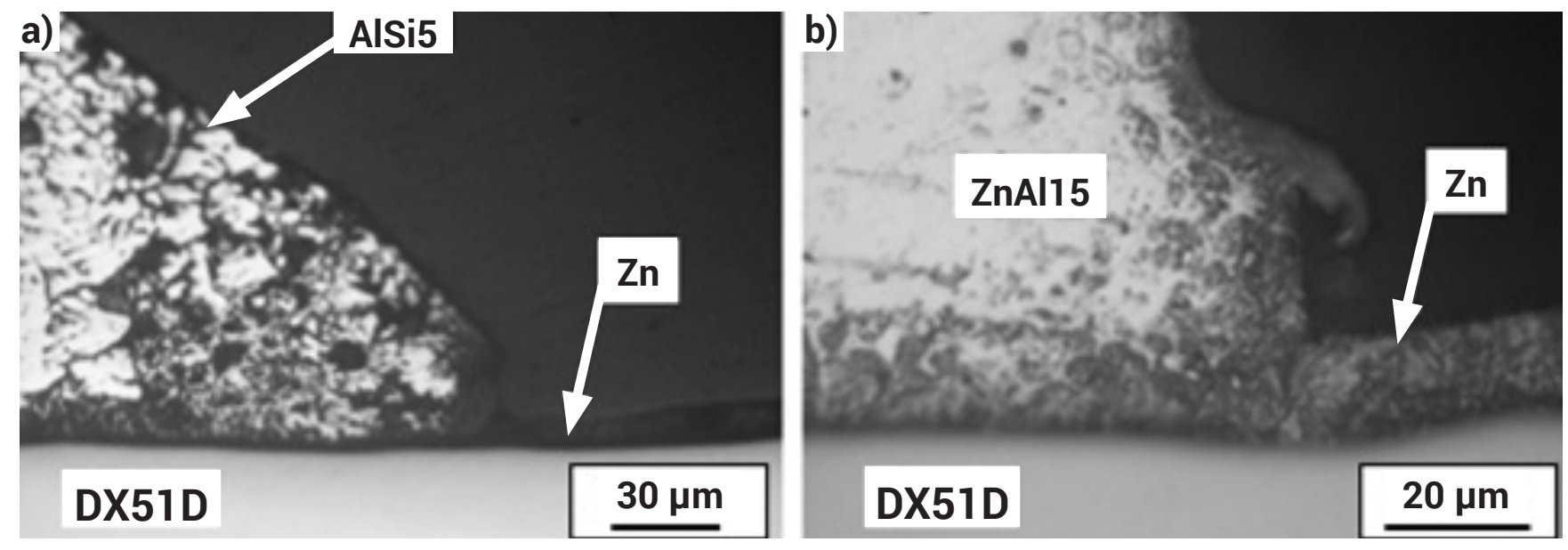

Rys. 5. Mikrostruktury złączy lutospawanych wykonanych przy użyciu spoiwa: a) AlSi5 i b) ZnAl15, widok w strefie początkowej lutospoiny Fig. 5. Microstructure of braze-welded joints made using a filler metals: a) AlSi5 and b) ZnAl15, view in the initial zone of braze-weld
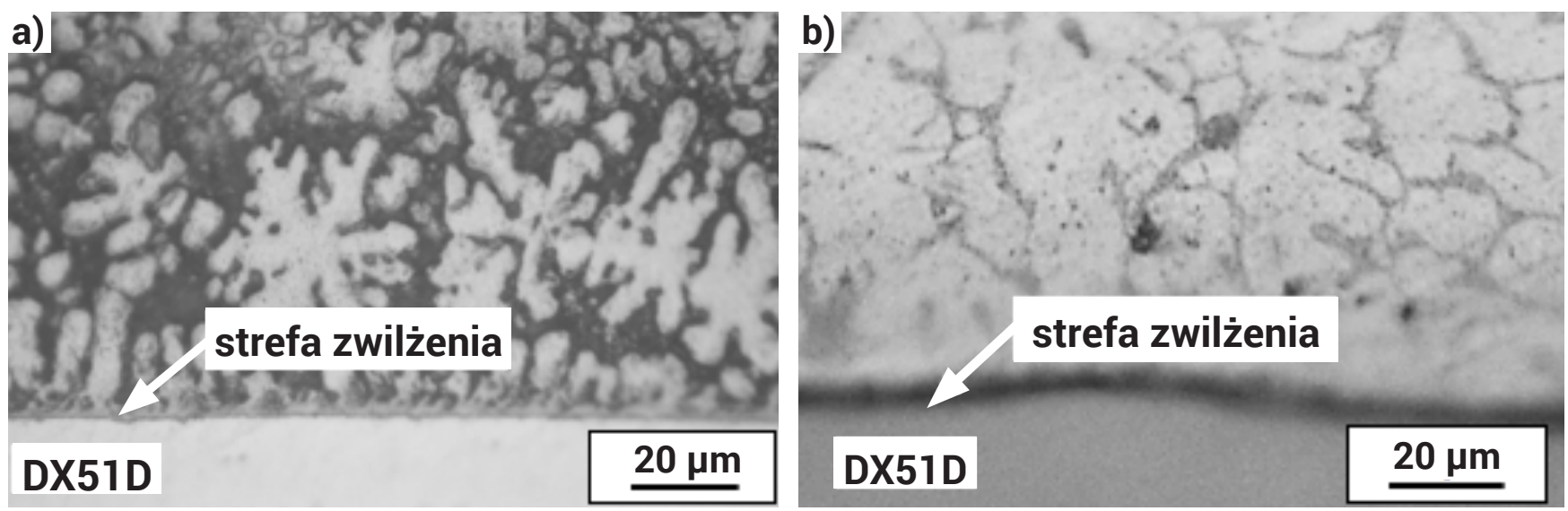

Rys. 6. Mikrostruktury złączy lutospawanych wykonanych przy użyciu spoiwa: a) AlSi5 i b) ZnAl15

Fig. 6. Microstructure of braze-welded joints made using a filler metals: a) AlSi5 and b) ZnAl15

\section{Wnioski}

Na podstawie przeprowadzonych badań można sformułować następujące wnioski:

- metoda lutospawania CMT umożliwia uzyskanie poprawnych złączy zakładkowych o estetycznym wyglądzie z cienkich blach (o grubości 1,0 mm), bez uszkodzenia warstwy cynku zarówno na brzegu lutospoiny, jak i po stronie przeciwnej złącza;

- rodzaj spoiwa użytego do wykonania złącza ma znaczący wpływ na jego wytrzymałość mechaniczną. Użycie spoiwa na bazie cynku umożliwia uzyskanie złączy o wytrzymałości $185 \mathrm{MPa}$, która w przybliżeniu odpowiada wytrzymałości stopu aluminium 5754 w stanie wyżarzonym występującym w SWC lutospoiny. Wytrzymałość złączy wykonanych przy użyciu spoiwa na bazie aluminium jest o ok. $75 \%$ mniejsza i wynika z większego przegrzania stopu aluminium w SWC;

- złącza wykonane przy użyciu spoiwa ZnAl15 posiadają mniejszą ilość niezgodności wewnętrznych w postaci pęcherzy gazowych, usytuowanych w górnej części lutospoiny;

- spoiwo na bazie aluminium AISi5 lepiej zwilża powierzchnię stalowej ocynkowanej blachy umożliwiający uzyskanie lutospoiny o bardziej płaskim licu.

\section{Literatura}

[1] Górka J., Kupiec K.: Technologia lutospawania TIG stalowych ocynkowanych blach karoseryjnych, Biuletyn Instytutu Spawalnictwa 4/2009, s. 62-66.

[2] Klimpel A., Czypryński A., Górka J.: Lutospawanie metodą GMA cienkich blach ocynkowanych, Przegląd Spawalnictwa 8-9/2004, s. 81-85.

[3] Matusiak J., Czwórnóg B.: Niskoenergetyczne procesy spawania łukowego w osłonie gazów do łączenia cienkich blach stalowych, Hutnik - wiadomości hutnicze 2008.

[4] Węglowski M., Chmielewski T., Kudła K.: Ocena wydajności spawania niskoenergetycznego procesu SpeedRoot w pozycji PG, Przegląd Spawalnictwa, nr 12/2011.

[5] Białucki P., Ambroziak A., Derlukiewicz W., Lange A., Glezman M.: Właściwości złączy lutospawanych aluminium ze stalą, Przegląd Spawalnictwa, nr 9/2013, s. 40-44.

[6] Jakubowski J., Bober M., Rudaś T.: Struktura złączy lutospawanych metodą CMT stali ocynkowanej ogniowo, Przegląd Spawalnictwa, nr 9/2013, s. 45-49.

[7] Himmelbauer K.: The CMT process - a revolution in welding Technology, IIW Doc. no. XII- 1875-05.

[8] PN-EN 10346:2015-09 Wyroby płaskie stalowe powlekane ogniowo w sposób ciągły do obróbki plastycznej na zimno - Warunki techniczne dostawy.

[9] PN-EN 485-2:2016-10 Aluminium i stopy aluminium - Blachy, taśmy i płyty - Część 2: Własności mechaniczne.

[10] PN-EN 573-3:2014-02 Aluminium i stopy aluminium - Skład chemiczny i rodzaje wyrobów przerobionych plastycznie - Część 3: Skład chemiczny i rodzaje wyrobów.

[11] PN-EN ISO 3677:2016-12 Spoiwa do lutowania miękkiego i twardego - Oznaczenie. 